\title{
Corolla size and temporal displacement of flowering times among sympatric diploid and tetraploid highbush blueberry (Vaccinium corymbosum)
}

\begin{tabular}{|r|l|}
\hline Journal: & Botany \\
\hline Manuscript ID & cjb-2016-0137.R1 \\
\hline Danuscript Type: & Article \\
\hline Complete List of Authors: & $\begin{array}{l}\text { Poster, Lauren; Rutgers University, Ecology and Evolution } \\
\text { Handel, Steven; Rutgers University New Brunswick, Ecology, Evolution, \& } \\
\text { Natural Resources } \\
\text { Smouse, Peter; Rutgers University New Brunswick, Ecology, Evolution \& } \\
\text { Natural Resources }\end{array}$ \\
\hline Keyword: & $\begin{array}{l}\text { flowering phenology, New Jersey, polyploidy, corolla size, Vaccinium } \\
\text { corymbosum }\end{array}$ \\
\hline & \multicolumn{2}{|c}{} \\
\hline
\end{tabular}

SCHOLARONE

Manuscripts 


\title{
Corolla size and temporal displacement of flowering times among sympatric diploid and tetraploid highbush blueberry (Vaccinium corymbosum) ${ }^{1}$
}

\author{
Lauren S. Poster 2, 3, 4, Steven N. Handel ${ }^{4}$, Peter E. Smouse ${ }^{4}$ \\ ${ }^{1}$ Manuscript received \\ ; revision accepted \\ ${ }^{2}$ Author for correspondence: 1 College Farm Rd, New Brunswick, NJ 08901. E-mail: \\ Ls.poster@rutgers.edu) \\ ${ }^{3}$ Graduate Program in Ecology \& Evolution, Rutgers University, New Brunswick, NJ \\ 08901, USA \\ ${ }^{4}$ Department of Ecology, Evolution, \& Natural Resources, Rutgers University, New \\ Brunswick, NJ 08901, USA
}

$\underline{\text { Running Head: }}$

Flowering times of sympatric $2 \mathrm{x}$ and $4 \mathrm{x}$ highbush blueberries 


\section{ABSTRACT}

Polyploidy (whole-genome duplication) is common in vascular plants, but the modes of establishment and persistence, as well as the ecological consequences, of polyploidy remain vague. Highbush blueberry (Vaccinium corymbosum L.) is an ecologically and economically important understory shrub with an unclear species definition, coexisting in sympatric populations of diploid and tetraploid cytotypes. This study analyzes differences in bloom time between sympatric diploid and tetraploid V. corymbosum in natural populations, testing the potential for these cytotypes to interbreed and contributing to the formation and continuity of ploidylevel diversification within this species.

Ploidal level was confirmed through DNA flow cytometry of sympatric plants from two populations in New Jersey, USA. Flower bloom date and corolla size were recorded over a three-year period. Diploid corollas were $32 \%$ smaller than tetraploid corollas, making them easily identifiable in the field. Ploidy accounted for $55-69 \%$ of the variation in bloom date, with diploids flowering about one week before tetraploids, and the remaining variation distributed among plants, among branches, and within branches. Notwithstanding these differences, there was modest overlap in flowering time between cytotypes, suggesting that crosspollination is possible. This contributes evidence to the most current species definition of $V$. corymbosum as a single (mixed ploidy) species.

Key Words: corolla size; flowering phenology; highbush blueberry; New Jersey; polyploidy; Vaccinium corymbosum 


\section{INTRODUCTION}

Although previously thought to be an evolutionary dead-end (Stebbins, 1950; Levin, 2002; Mayrose et al. 2011) polyploidy, or whole genome duplication, is now understood to be ubiquitous among angiosperms and found extensively among green plants (Soltis and Soltis, 2000; Husband et al., 2013; Soltis et al., 2014;). Polyploid formation is generally recurrent (Soltis and Soltis, 1993), yet the factors for establishment, persistence, and success of polyploids are still poorly understood and must be evaluated on a case-by-case basis (Stebbins, 1980; Soltis and Soltis, 2009; Visger et al. 2016). Polyploids can only persist if they can outcompete their diploid progenitors or can occupy new niches, via morphological and physiological changes. These changes in ecological adaption, known as the niche shift hypothesis (Levin, 1975; Husband and Schemske, 2000; Maherali et al. 2009; Ramsey, 2011; Levin, 2011; Glennon et al., 2014), contrast with the traditional null hypothesis of niche conservatism, where polyploids and their diploid progenitors are thought to have similar ecological requirements because they are close relatives (Godsoe et al., 2013; Glennon et al., 2014).

Polyploidy is known to affect plant cell size (Stebbins, 1971; Masterson, 1994), genetic variation (Stebbins, 1950; Husband and Schemske, 1997; Soltis and Soltis, 2000; Levin, 2002; Soltis et al., 2014), and physiology (Stebbins, 1985; Li et al., 1996; Soltis and Soltis, 2000; Levin, 2002; Maherali et al., 2009). It also affects morphology (Giles, 1942; Stebbins, 1950; Vander Kloet, 1980; Stebbins, 1985; Segraves and Thompson, 1999; Levin, 2002), phenology (Garbutt and Bazzaz, 1983; Segraves and Thompson, 1999; Husband and Schemske, 2000; Thompson and Merg, 
2008), and geographic distribution (Giles, 1942; Fowler and Levin, 1984; Stebbins, 1985; Thompson and Lumaret, 1992; Levin, 2002; Treier et al, 2009; Levin, 2011). Any combination of those effects might contribute to the ubiquity and success of polyploids in nature.

Some studies have shown that such changes have pushed polyploids into different ecological niches than their diploid progenitors, supporting the niche shift hypothesis (Giles, 1942; Treier et al., 2009; Levin, 2011; Visger et al., 2016).

However, other recent studies have shown no shift in ecological niche between diploids and their polyploid counterparts (Godsoe et al., 2013; Glennon et al., 2014.) Many polyploid lines are thought to become extinct during the initial establishment phase (Stebbins, 1985; Levin, 2002; Mayrose et al. 2011; Godsoe et al. 2013). Levin (1975) offered a minority cytotype exclusion theory (henceforth, MCE), the central feature being that interbreeding between common diploids and rare polyploids produces infertile inter-cytotype hybrids; thus, diploid pollen swamping would impede the establishment of the minority (polyploidy) cytotype.

Mechanisms that limit inter-cytotype matings, such as shifts in flowering phenology (Segraves and Thompson, 1999; Husband and Schemske, 2000; Godsoe et al. 2013), changes in floral traits that impact pollination and pollinator preference (Segraves and Thompson, 1999; Husband and Schemske, 2000), or spatial segregation of cytotypes (Fowler and Levin, 1984; Thompson and Lumaret, 1992; Ramsey, 2011; Visger et al. 2016), could potentially contribute to polyploid establishment and success. If polyploids can escape MCE by mating within their own niche, separated from diploid gametes, genome-doubling events can lead to 
speciation events, either instantaneously or over time via natural selection (Segraves and Thompson, 1999; Maherali et al., 2009; Ramsey, 2011).

This study examines pre-zygotic mating barriers in natural sympatric populations of diploid and tetraploid highbush blueberries (Vaccinium corymbosum L., family Ericaceae). These polyploids have avoided MCE and established themselves as persistent populations by means other than spatial segregation. We specifically focus on floral traits and flowering phenology and how these affect sterile inter-ploidal mating.

Blueberries are an important agricultural crop worldwide (Eck and Childers, 1966; Eck, 1988), but they are also ecologically important native shrubs in habitats along the eastern and southern coast of the United States, inland to Texas and Wisconsin, and as far north as Ontario and eastern Canada. Morphological, ecological, and genetic differences within the genus complicate the taxonomy of Vaccinium, and the status of highbush blueberry, in particular, is unclear. Highbush blueberry has most recently been considered one polymorphic species, Vaccinium corymbosum L. (Vander Kloet, 1980; eFloras, 2008) containing diploids, tetraploids, and hexaploids, but the complex has been separated into as many as 12 different species over the years (Camp, 1945). Triploids and pentaploids are generally inviable (Vorsa and Ballington, 1991).

Vander Kloet (1980) reported no gross morphological characters that would separate these cytotypic gene pools, but anecdotal information provided by blueberry researchers and growers suggest that subtle distinctions do exist (Nicholi Vorsa, personal communication; Gary Pavlis, personal communication). In 
particular, tetraploid highbush blueberry flowers are larger than diploid flowers and tetraploids bloom later than diploids. Additionally, all cultivated varieties of $V$. corymbosum are tetraploid, producing larger and more abundant fruit (Ortiz et al., 1992a). There have been no formal studies of ploidal level differences associated with ecology, morphology, or phenology, either in the greenhouse or in the wild. If there are, in fact, differences among the cytotypes that strongly affect gene flow, then taxonomic separation may yet be in order.

If Vander Kloet's (1980) classification of V. corymbosum as a single, polymorphic species is apt, however, there must be at least episodic gene flow among (2x, 4x and $6 \mathrm{x})$ cytotypes. Ortiz et al. (1992b) found that a substantial amount of unreduced ( $2 \mathrm{n})$ pollen was produced by diploid Vaccinium spp. If tetraploids are produced by sexual means, i.e., by combining unreduced ( $2 \mathrm{n}$ ) diploid gametes, these (2n) gametes might well continue providing (unidirectional) gene flow from the diploid into the tetraploid population. In seven diploid species examined, an average of $13.5 \%$ of individuals produced unreduced pollen grains, and as much as $30 \%$ of the pollen produced by diploid individuals was itself diploid (Ortiz et al., 1992a), suggesting that there might be at least a modicum of gene flow between sympatric diploid and tetraploid individuals.

Here, we will test: (1) whether corolla size varies between cytotypes, which could influence pollinator preference; (2) whether there is a phenological offset in bloom time between sympatric diploid and tetraploid highbush blueberries in New Jersey populations; and (3) whether there is sufficient overlap in bloom time to allow for genetic exchange between sympatric cytotypes. This information will help 
define the Vaccinium corymbosum species complex, provide some insight into the likely future of this important species, and will contribute to our understanding of polyploid establishment and persistence in general.

\section{MATERIALS AND METHODS}

Vaccinium corymbosum L. (Ericaceae) is a perennial, crown-forming, multistemmed shrub (2-4 meters tall) with leaves that are deciduous, alternate, simple, elliptic or ovate, $3.8-8.2 \mathrm{~cm}$ long, glaborous or glaucous beneath, with margins that are entire, subserrate, or sharply serrate. The corolla is urn-shaped and white, and berries are dull black or blue, $4-12 \mathrm{~mm}$ in diameter. Flowering occurs between February and June, while fruiting occurs between April and October, depending on the location. The most common native habitats are in open swamps and bogs of moderate to high acidity, around marshes, swamps, and lakes, pine barrens, upland woods and ravines, and pine-oak woods. The species complex is widespread in eastern North America, ranging from Nova Scotia to Ontario, Maine to Wisconsin, and south to Texas and Florida (Vander Kloet, 1980; USDA Plants Database, 2016). Diploids $(2 \mathrm{n}=2 \mathrm{x}=24)$, tetraploids $(2 \mathrm{n}=4 \mathrm{x}=48)$, and hexaploids $(2 \mathrm{n}=6 \mathrm{x}=72)$ occur sympatrically throughout the range, although diploids tend to be more common in the southeastern United States, and tetraploids, being more cold tolerant, in the northeastern United States and Canada. Hexaploids are found in a few isolated populations on mountain summits along the Blue Ridge in the southeastern United States (Vander Kloet, 1980). Vaccinium corymbosum is mainly bee-pollinated, with seeds that are widely dispersed by birds and mammals. 
Highbush blueberry is the main blueberry used for cultivation, which began 100 years ago in New Jersey (Coville, 1910; Coville 1916). Blueberries are now extensively cultivated in New Jersey, Michigan, North Carolina, Florida, Massachusetts, and Washington (USDA Plants Database, 2016).

First year of study - In April 2013, branch samples were collected from wild diploid and tetraploid Vaccinium corymbosum plants, growing in a mixed population along the perimeter of the Philip E. Marucci Center for Blueberry and Cranberry Research and Extension, a substation of the New Jersey Agricultural Experiment Station of Rutgers University in Chatsworth, Burlington County, New Jersey $\left(39.71543^{\circ} \mathrm{N},-74.51046^{\circ} \mathrm{W}\right)$. Ploidy was initially estimated using morphological floristic characters (larger corollas were considered polyploids). Three branches from each plant were cut and immediately put into buckets of water. Branch samples were selected based on having at least 10 flower buds, which were generally found in clusters of 4-5 (rarely 2-10) flowers each. The branches were immediately transported to a local greenhouse and kept outside in full sun in buckets of water.

Eight diploid and eight tetraploid plants were studied. Ten flower buds were marked on each of the three branches per plant, and bloom date was recorded for each flower. We selected the first 10 flower buds from the tip on the branch below the leader branch. The number of open flowers was recorded 2-3 times per week until all flowers had opened and senesced. Flowers were considered "open" when the tips of the corolla lobes were recurved. We randomly selected five diploid branches and seven tetraploid branches, each from a different plant. The first five 
open flowers closest to the base of the branch were measured and recorded for corolla size.

Second and third years of study - A natural population of mixed diploid and tetraploid V. corymbosum was flagged at the Great Swamp National Wildlife Refuge (Basking Ridge, Morris County, New Jersey; $40.70421^{\circ} \mathrm{N},-74.49526^{\circ} \mathrm{W}$ ) in the spring of 2013. This site has not been disturbed for at least the past 100 years. Twenty diploid plants and twenty tetraploid plants were used in this part of the study. Voucher specimens were deposited at the Chrysler Herbarium of Rutgers University (Poster, s.n., 7 May 2014; CHRB145201 - CHRB145208).

In April 2014 and 2015, flower buds were marked on each plant, following the same protocol as used for the 2013 study, except that the branches were not cut off, and only two branches per plant were marked. The number of open flowers was recorded 2-3 times per week until all flowers had opened and senesced. Duration of bloom time for each flower was also recorded. Flowers were considered to be finished blooming when their corollas abscised. The same plants were used in both 2014 and 2015, but different branches and clusters of buds were used because almost none of the branches used in 2014 had flower buds on them in 2015.

Ploidy analysis -_Ploidal levels were confirmed through DNA flow cytometry (Costich et al., 1993) performed by Plant Cytometry Services (Laageinde 6, 4016 CV Kapel Avezaath Buren, The Netherlands). Young leaf samples of at least $3 \mathrm{~cm}^{2}$ in total area were collected from at least 2 different branches on each plant used in the study (57 plants from the Great Swamp site and 27 plants from the Marucci site; not all plants analyzed for ploidal level were used in the final analysis). 
Leaf material was chopped with a sharp razor blade in an ice-cold DNA (DAPI) buffer, containing Cystain UV precise P from Partec with 0.1\% DTT (Dithiothreitol) and 1\% PVP 10, in a plastic petri dish. When an internal standard was used, fresh material of the standard was chopped together with the other leaf material. After chopping, the solution was passed through a $50 \mu$ m nylon mesh filter to isolate the nuclei. The stained nuclei were sent through the flow cytometer (CyFlow Space with a UV high power LED, Partec GmbH, Otto Hahnstrasse 32, D4400 Munster, Germany) where fluorescence was measured by a photomultiplier, converted into voltage pulses, and processed by a computer to yield integral and peak signals (Flomax version 2.8, Partec).

Statistical analysis - The Welch $t$-test was used to compare diploid and tetraploid averages of corolla length and width. We used ANOVA to determine variation in bloom date within diploids and within tetraploids, apportioning the variance among contributing factors. We estimated the variation among flowers $\left(\mathrm{V}_{\mathrm{AF}}\right)$, among branches $\left(\mathrm{V}_{\mathrm{AB}}\right)$, and among plants $\left(\mathrm{V}_{\mathrm{AP}}\right)$ for each of the cytotypes, as well as among cytotypes $\left(\mathrm{V}_{\mathrm{AC}}\right)$, starting from a matrix of pairwise flowering time differences among all pairs of flowers in the sample, using the AMOVA Routine in GenAlEx 6.503 (http://biology.anu.edu.au/GenAlEx/); Peakall and Smouse, 2006, 2012). This program is typically used for analysis of molecular variance of genetic markers, but any character set presented as a matrix of squared inter-pair distances (as computed from our flowering time dates here) can be used. We used a nonparametric (permutational) analogue of Bartlett's test (Snedecor and Cochran, 
Highbush Blueberry Phenology

Poster et al. 11

1989) of variance homogeneity to compare flowering-time variances of diploid and tetraploid plants, separately for the collections of 2013, 2014, and 2015.

\section{RESULTS}

Floral morphology - Combining the two field sites, a total of 45 diploid plants and 41 tetraploid plants were marked. Based on a random sample of flowers (26 diploid and 33 tetraploid), we found that diploid flowers had a corolla length ranging from $4.7 \mathrm{~mm}-7.4 \mathrm{~mm}($ mean $=5.7 \mathrm{~mm} \pm 0.13 \mathrm{~mm})$ and a corolla width of $2.3 \mathrm{~mm}-4.9$ $\mathrm{mm}($ mean $=3.7 \mathrm{~mm} \pm 0.11 \mathrm{~mm})$, and tetraploid flowers had a corolla length ranging from $7.6 \mathrm{~mm}-10.4 \mathrm{~mm}($ mean $=9.0 \mathrm{~mm} \pm 0.14 \mathrm{~mm})$ and a corolla width of $3.9 \mathrm{~mm}$ $-6.3 \mathrm{~mm}($ mean $=5.1 \mathrm{~mm} \pm 0.11 \mathrm{~mm})($ Fig. 1 and 2$)$. Welch $t$-tests of corolla length and widths differences between diploids and tetraploids were significant $(P<$ 0.0001). Of the 86 plants we classified based on corolla size, only one was found to be identified incorrectly following DNA flow cytometry.

[Figure 1 - about here] [Figure 2 - about here]

Floral phenology - In all three years, diploid flowers began blooming between 23 April and 25 April; peak diploid bloom was between 28 April and 7 May; and final dates of bloom ranged from 11 May to 25 May (Fig. 3). Tetraploid flowers first bloomed between 24 April and 2 May; peak bloom was between 6 May and 20 May; and final bloom was between 16 May and 28 May. In 2013, there was an 8-day lag between peak diploid and peak tetraploid bloom dates. In 2014, there was a 7-day lag. In 2015, there was only a 3-day lag between peak diploid and peak tetraploid bloom dates, but we may have missed the actual peak bloom for the diploids (there 
was a 5-day gap between sampling dates, 30 April to 5 May, due to logistical and weather constraints; see "2015 2x" in Fig. 3).

[Figure 3 - about here]

Peak bloom dates were about one week later in 2014 than in 2013 (Fig. 3). This was most likely due to an extremely cold winter in 2014 lasting well into the spring season. Both diploid and tetraploid flowers also stayed open for the longest period of time in 2014 (30 days for diploids and 26 days for tetraploids, versus 19 and 22 days, respectively, in 2013, and 18 and 23 days, respectively, in 2015, Fig. 3). This probably reflects the long winter and subsequent cooler spring in 2014. Peak bloom dates in 2015 fell in between the peak bloom dates of 2013 and 2014. While there was yearly climatic variation, the patterns for all three years were similar.

ANOVA showed, for both diploids and tetraploids, that temporal variation among flowers on the same plant accounted for $41-61 \%$ of the total variation within diploids and tetraploids across all three years (Fig. 4). Among branch variation accounted for $8-20 \%$ of the total variation, and among plant variation accounted for $23-42 \%$ of the total variation. The distribution of variation within diploids and within tetraploids was similar in all three years (Fig. 4).

\section{[Figure 4 - about here]}

Bartlett's test of homogeneity of variance showed that the total variances within diploids and within tetraploids were significantly different $(P<0.001)$ in both 2013 and 2015, but in 2014, the total variances were not significantly different $(P=0.588)$. In 2013 , the tetraploids exhibited greater variance than the diploids, but that was reversed in 2015 , and in 2014 , the variances were similar. 


$$
\left[\left(\frac{\mathrm{V}_{2 \mathrm{n}}}{\mathrm{V}_{4 \mathrm{n}}}\right)_{2013}=0.28, P<0.001\right]<\left[\left(\frac{\mathrm{V}_{2 \mathrm{n}}}{\mathrm{V}_{4 \mathrm{n}}}\right)_{2014}=0.95, P=0.588\right]<\left[\left(\frac{\mathrm{V}_{2 \mathrm{n}}}{\mathrm{V}_{4 \mathrm{n}}}\right)_{2015}=1.59, P<0.01\right]
$$

These results show that the variation in seasonal bloom period was different for the two cytotypes, but the size and the direction of that difference changed profoundly from year to year, despite being in the same location and experiencing the same climate.

[ Table 1 - about here ]

When comparing bloom dates within any single year, combining diploids and tetraploids, ploidy/cytotype $\left(\mathrm{V}_{\mathrm{AC}}\right)$ accounted for most of the variation, 55-69\% (Fig. 5; Table 2). If sampling of the tetraploids had continued in the first year (2013) until all flowers were finished blooming, the calculated mean would have accounted for more than $55 \%$ of the total variance. Variation among plants $\left(\mathrm{V}_{\mathrm{AP}}\right)$, within cytotypes, accounted for $15-20 \%$, among branch variation $\left(\mathrm{V}_{\mathrm{AB}}\right)$ accounted for 12 $18 \%$, and among flower variation $\left(\mathrm{V}_{\mathrm{AF}}\right)$ accounted for $4-7 \%$ of the total variation. Within each year, the variation was distributed similarly (Fig. 5), as we found in the previous analysis comparing within diploids to within tetraploids (Fig. 4). Year to year estimates of total variation were significantly different (Bartlett's test, $P<$ 0.001; Table 2), probably due to yearly climatic variation.

[Figure 5 - about here] [ Table 2 - about here ]

\section{DISCUSSION}


Corolla morphology and ploidy - Significant and consistent differences in corolla size were found between diploid and tetraploid highbush blueberry flowers. Tetraploid flowers were larger overall than diploids flowers. This is consistent with previous studies that found differences in morphological floral traits between polyploids and their diploid progenitors, with tetraploid flowers being larger than diploids (Giles, 1942; Garbutt and Bazzaz, 1983; Segraves and Thompson, 1999; Husband and Schemske, 2000; Maherali et al. 2009). This difference can easily be used to separate diploid and tetraploid $V$. corymbosum visually in mixed populations. Larger organ size is thought to be a direct effect of chromosome doubling, as polyploids generally have larger cell size due to higher DNA content (Stebbins, 1971; Masterson, 1994).

Flower morphology may affect other pre-zygotic isolating factors that limit gene exchange between cytotypes, particularly pollinator preference (Garbutt and Bazzaz, 1983; Segraves and Thompson, 1999; Husband and Schemske, 2000). For example, Blarer et al. (2002) found that larger flowers often contained larger nectar rewards and received more pollinator visits than smaller flowers. Galen and Newport (1987) found that bumblebees visited larger flowers more often, but deposited fewer outcross pollen grains per visit (i.e., lower pollination efficiency) on Polemonium viscosum Nutt.. Thompson and Merg (2008) found that some pollinators preferentially visited one cytotype over the other in mixed sympatric populations of diploid and polyploid Heuchera grossulariifolia Rydb. Future studies on the ecological impacts of flower morphology, particularly pollinator preference, 
would be useful in further assessing gene flow and potential reproductive isolation between sympatric diploid and tetraploid populations of $V$. corymbosum.

Flowering separation and overlap - Despite significantly different levels of phenological variation from year to year, the two cytotypes showed remarkably similar internal distributions of the total variation, within and among plants, within and among branches, for all three years $\left(V_{A F}>V_{A P}>V_{A B}\right.$, Fig. 4; and $V_{A C}>V_{A P}>V_{A B}>$ $\mathrm{V}_{\mathrm{AF}}$; Fig. 5). This implies that the phenological process is generally conserved among cytotypes, regardless of chromosome doubling.

Although the 2015 data only showed a 3-day difference in peak bloom date (Fig. 3), we may have missed the peak diploid bloom date that year due to a 5-day gap in sampling. Overall, our data suggest an average difference in peak bloom date between diploids and tetraploids of approximately one week. Tetraploids have also been found to flower approximately one week later than diploids in Chamerion angustifolium (L.) Holub (Onagraceae) (Husband and Schemske, 2000; Maherali et al., 2009). However, Segraves and Thompson (1999) found that tetraploids bloomed earlier than diploids in Heuchera grossulariifolia. A shift in timing of flowering phenology, whether earlier or later, is nonetheless a shift in niche utilization, which most likely contributes to the success of polyploids in these situations. Yet, the inconsistency of the direction of the shift illustrates the difficulty in predicting physiological and morphological effects of chromosome doubling.

Despite this difference in peak bloom date, we observed modest overlap between diploid and tetraploid flowering dates. Coinciding flowering time, combined with high rates of unreduced gametes (Ortiz et al., 1992a and 1992b), 
could provide, at least, an opportunity for genetic exchange between cytotypes. Gene flow, if occurring, would be unidirectional, from diploids to tetraploids via the $2 \mathrm{n}$ unreduced gametes produced by the diploid plants. Intercytotype crossings in blueberries performed in the greenhouse have resulted in few viable plants (Ballington and Galletta, 1976, recovered 3 seedlings per 1000 pollinations; Vander Kloet, 1980, recovered 13 plants after four years of crossing trials), however, heteroploid crossings have not been tested in the field. If genetic exchange is occurring consistently across populations, this would certainly support the most recent taxonomic treatment of the highbush blueberries (eFloras, 2008; Vander Kloet, 1980), in which Vaccinium corymbosum is treated as one polymorphic species.

Nonetheless, co-flowering is not evidence of cross-breeding. There could be other pre-zygotic and/or post-zygotic mating barriers preventing gene flow between the cytotypes, such as pollinator preference or triploid block (Husband and Schemske, 2000), which could reinforce cytotypic subdivivision, and even speciation. The proven overlap in flowering times among sympatric populations of mixed cytotypes found in this study calls for further examination of direct evidence for or against genetic exchange before being able to fully support the single polymorphic species definition of this group.

It is unclear how the cytotypes of Vaccinium corymbosum are performing in the wild. Vander Kloet (1980; p. 1191) suggests that, "these gene pools, at the utmost, might be considered species in statu nascendi." We may be at a point in blueberry evolutionary history where these cytotypes are beginning to differentiate themselves into separate species. Although other ecological differences remain to 
be documented, the differences found in the reproductive characters studied here support the conclusion that ploidy variation within an interbreeding polyploid series will almost surely influence microevolutionary processes, and possibly lead to speciation events.

These reproductive differences may have applied consequences. Highbush blueberries are commonly used in habitat restoration throughout their range, but the importance of ploidy variation in developing new economic products and populations most useful for ecological restoration initiatives remains vague (Handel et al., 1994; Hufford and Mazer, 2003; Handel et al., 2013.). Planting success is a necessary contractual part of restoration projects, and effects of chromosome doubling, such as phenology and corolla size as it relates to pollinator preference, may play an important role in plant survival. The New York Metropolitan Flora Project has found that nearly all members of the heath family (Ericaceae), including V. corymbosum, in its 25 county study area have experienced decreasing range sizes over the past 100 years, with a corresponding decrease in abundance (Clemants and Moore, 2005). More precision in restoration ecology initiaves may counter this regional decline. Knowledge of additional ecological traits between the cytotypes may advance these economic uses. 


\section{ACKNOWLEDGEMENTS}

The authors thank Dr. Nicholi Vorsa and the Philip E. Marucci Center for Blueberry and Cranberry Research and Extension at Rutgers University for providing invaluable information, resources, and access to the field site; Steven Henry and Michael Horne, and the Great Swamp National Wildlife Refuge for information and access to the field site; Glenn Rogers and the Pinelands Nursery and Supply for providing propagation information and supplies; and Kristine Rogers, Rachel Rodriguez, and Michelle Segovia for their help with fieldwork. The authors also thank two anonymous reviewers and the editors at Botany for the helpful comments to improve the manuscript. LSP was supported by the Bayard Long Award from the Philadelphia Botanical Club, the Rogers McVaugh Graduate Student Research Grant from the American Society of Plant Taxonomists, and a Small Grant for Graduate Student Research in Ecology and Evolution from Rutgers University; SNH was supported by funding from a National Institute of Food and Agriculture Hatch / Multistate grant NJ17205; PES was supported by USDA/NJAES-17160. 


\section{REFERENCES}

Ballington, J.R., and Galletta, G.J. 1976. Potential fertility levels in four diploid Vaccinium species. J. Am. Soc. Hortic. Sci. 101: 507-509.

Blarer, A., Keasar, T., and Shmida A. 2002. Possible mechanisms for the formation of flower size preferences by foraging bumblebees. Ethol. 108(4): 341-351. doi:10.1046/j.1439-0310.2002.00778.x.

Camp, W.H. 1945. The North American blueberries with notes on other groups of Vacciniaceae. Brittonia 5(3): 203-275. doi:10.2307/2804880.

Clements S. E. and Moore, G. 2005. The changing flora of the New York metropolitan region. Urban Habitats 3(1): 192-210. doi:10.5860/choice.42-4381.

Costich, D.E., Ortiz, R., Meagher, T.R., Bruederle, L.P., and Vorsa, N. 1993.

Determination of ploidy level and nuclear DNA content in blueberry by flow cytometry. Theor. Appl. Genet. 86: 1001-1006. doi:10.1007/bf00211053. PMID: 24194009.

Coville, F.V. 1910. Experiments in Blueberry Culture. U.S. Department of Agriculture, Bureau of Plant Industry, Bull. No. 193, Washington, D.C., 100pp.

Coville, F.V. 1916. Directions for Blueberry Culture. U.S. Department of Agriculture, Bureau of Plant Industry, Bull. No. 334, Washington, D.C. 16 pp. and XVII plates. doi:10.5962/bhl.title.108248.

Eck, P. 1988. Blueberry science. Rutgers University Press, New Brunswick, New Jersey, USA.

Eck, P., and Childers, N.F. 1966. Blueberry culture. Rutgers University Press, New Brunswick, New Jersey, USA. 
eFloras. 2008. Flora of North America. Published on the Internet <http://www.efloras.org>, [accessed 14 July 2014]. Missouri Botanical Garden, St. Lous, MO \& Harvard University Herbaria, Cambridge, MA.

Fowler, N.L., and Levin, D.A. 1984. Ecological constraints on the establishment of a novel polyploidy in competition with its diploid progenitor. Amer. Nat. 124(5): 703-711. doi:10.1086/284307.

Galen, C. and Newport, M.E.A. 1987. Bumble bee behavior and selection on flower size in the sky pilot, Polemonium viscosum. Oecologia 74(1): 20-23. doi:10.1007/bf00377340.

Garbutt, K., and Bazzaz, F.A. 1983. Leaf demography, flower production and biomass of diploid and tetraploid populations of Phlox drummondii Hook. on a soil moisture gradient. New Phytol. 93: 129-141. doi:10.1111/j.14698137.1983.tb02698.x.

Giles, N.H. 1942. Autopolyploidy and geographical distribution in Cuthbertia graminea Small. Am. J. Bot. 29(8): 637-645. doi:10.2307/2437176.

Glennon, K.L., Ritchie, M.E., and Segraves, K.A. 2014. Evidence for shared broad-scale climatic niches of diploid and polyploidy plants. Ecol. Lett. 17: 574-582. doi:10.1111/ele.12259.

Godsoe, W., Larson, M.A., Glennon, K.L., and Segraves, K.A. 2013. Polyploidization in Heuchera cylindrica (Saxifragaceae) did not result in a shift in climatic requirements. Am. J. Bot. 100(3): 496-508. doi:10.3732/ajb.1200275. 
Handel, S.N., Robinson, G.R., and Beattie, A.J. 1994. Biodiversity resources for restoration ecology. Restoration Ecol. 2: 230-241. doi:10.1111/j.1526100x.1994.tb00055.x.

Handel, S.N., Saito, O., and Takeuchi, K. 2013. Restoration ecology in an urbanizing world. Urbanization, biodiversity and ecosystem services: challenges and opportunities, a global assessment. Edited by Elmqvist, T. and Fragkias, M. pp. 665-698. doi:10.1007/978-94-007-7088-1_31.

Hufford, K.M., and Mazer, S.J. 2003. Plants ecotypes; genetic differentiation in the age of ecological restoration. Trends Ecol. Evol. 18 (3); 147-155. doi:10.1016/s0169-5347(03)00002-8.

Husband, B.C., and Schemske, D.W. 1997. The effect of inbreeding in diploid and tetraploid populations of Epilobium angustifolium (Onagraceae): Implications for the genetic basis of inbreeding depression. Evolution 51(3): 737-746. doi:10.2307/2411150.

Husband, B.C., and Schemske, D.W. 2000. Ecological mechanisms of reproductive isolation between diploid and tetraploid Chamerion angustifolium. J. Ecol. 88: 689-701. doi:10.1046/j.1365-2745.2000.00481.x.

Husband, B.C., Baldwin, S.J., and Suda, J. 2013. The incidence of polyploidy in natural plant populations: Major patterns and evolutionary processes. In Plant genome diversity. Edited by Leitch, I., Greilhuber, J., Dolezel, J., and Wendel, J.F. Springer, Vienna, Austria. pp. 255-276. doi:10.1007/978-3-7091-1160-4_16.

Levin, D.A. 1975. Minority cytotype exclusion in local plant populations. Taxon 24(1): 35-43. doi:10.2307/1218997. 
Levin, D.A. 2002. The role of chromosomal change in plant evolution. Oxford University Press, New York, New York, USA. doi:10.1086/425787.

Levin, D.A. 2011. Polyploidy and ecological transfiguration in Achillea. Proc. Natl. Acad. Sci. U.S.A. 108(17): 6697-6698. doi:10.1073/pnas.1103568108.

Li, W., Berlyn, G.P., and Ashton, P.M.S. 1996. Polyploids and their structural and physiological characteristics relative to water deficit in Betula papyrifera (Betulaceae). Am. J. Bot. 83(1): 15-20. doi:10.2307/2445949.

Maherali, H., Walden, A.E., and Husband, B.C. 2009. Genome duplication and the evolution of physiological responses to water stress. New Phytol. 184: 721-731. doi:10.1111/j.1469-8137.2009.02997.x.

Masterson, J. 1994. Stomatal size in fossil plants: evidence for polyploidy in majority of angiosperms. Science 264: 421-424. doi:10.1126/science.264.5157.421.

Mayrose, I., Zhan, S.H., Rothfels, C.J., Magnuson-Ford, K., Barker, M.S., Rieseberg, L.H., and Otto, S.P. 2011. Recently formed polyploidy plants diversify at lower rates. Science 333: 1257-1257. doi:10.1126/science.1207205.

Ortiz, R., Bruederle, L.P., Laverty, T., and Vorsa, N. 1992a. The origin of polyploids via 2n gametes in Vaccinium section Cyannococcus. Euphytica 61: 241-246. doi:10.1007/bf00039664.

Ortiz, R., Vorsa, N., Bruederle, L.P., and Laverty, T. 1992b. Occurrence of unreduced pollen in diploid blueberry species, Vaccinium sect. Cyanococcus. Theor. Appl. Genet. 85: 55-60. doi:10.1007/bf00223844. PMID: 24197228.

Peakall, R. and Smouse, P.E. 2006. GenAlEx 6: genetic analysis in Excel. Population genetic software for teaching and research. Mol. Ecol. Notes. 6: 288-295. 
doi:10.1111/j.1471-8286.2005.01155.x.

Peakall, R. and Smouse, P.E. 2012. GenAlEx 6.5: genetic analysis in Excel. Population genetic software for teaching and research - an update. Bioinformatics 28: 2537-2539. doi:10.1093/bioinformatics/bts460.

Ramsey, J. 2011. Polyploidy and ecological adaptation in wild yarrow. Ed. Douglas Futuyma. Proc. Natl. Acad. Sci. U.S.A. 108(17): 7096-7101. doi:10.1073/pnas.1016631108.

Segraves, K.A., and Thompson, J.N. 1999. Plant polyploidy and pollination: Floral traits and insect visits to diploid and tetraploid Heuchera grossulariifolia. Evolution 53(4): 1114-1127. doi:10.2307/2640816.

Snedecor, G.W., and Cochran, W.G. 1989. Statistical Methods, Eighth Edition. Iowa State University Press. doi:10.3102/10769986019003304.

Soltis, P.S. and Soltis, D.E. 1993. Molecular data and the dynamic nature of polyploidy. Crit. Rev. Plant Sci. 12(3): 243-273. doi:10.1080/07352689309701903.

Soltis, P.S. and Soltis, D.E. 2000. The role of genetic and genomic attributes in the success of polyploids. Proc. Natl. Acad. Sci. 97(13): 7051-7057. doi:10.1073/pnas.97.13.7051.

Soltis, P.S. and Soltis, D.E. 2009. The role of hybridization in plant speciation. Annu. Rev. Plant Biol. 60: 561-588. doi:10.1146/annurev.arplant.043008.092039.

Soltis, D.E., Visger, C.J., and Soltis, P.S. 2014. The polyploidy revolution then...and now: Stebbins revisited. Am. J. Bot. 101(7): 1057-1078. doi:10.3732/ajb.1400178. 
Stebbins, G.L. 1950. Variation and evolution in plants. Oxford University Press, London, UK.

Stebbins, G.L. 1971. Chromosomal evolution in higher plants. London, UK: Edward Arnold Ltd.

Stebbins, G.L. 1980. Polyploidy in plants: Unsolved problems and prospects. In W.H. Lewis [ed.], Polyploidy: Biological Relevance, 495-520. Plenum Press, New York, New York, USA. doi:10.1007/978-1-4613-3069-1_26.

Stebbins, G.L. 1985. Polyploidy, hybridization, and the invasion of new habitats. Ann. Missouri Bot. Gard. 72: 824-832. doi:10.2307/2399224.

Thompson, J.D., and Lumaret, R. 1992. The evolutionary dynamics of polyploid plants: Origins, establishment and persistence. Trends Ecol. Evol. 7(9): 302-307. doi:10.1016/0169-5347(92)90228-4.

Thompson, J.N., and Merg, K.F. 2008. Evolution of polyploidy and the diversification of plant-pollinator interactions. Ecology 89(8): 2197-2206. doi:10.1890/071432.1.

Treier, U.A., Broennimann, O., Normand, S., Guisan, A., Schaffner, U., Steinger, T., and Muller-Scharer, H. 2009. Shift in cytotype frequency and niche space in the invasive plant Centaurea maculosa. Ecology 90(5): 1366-1377. doi:10.1890/080420.1.

USDA Plants Database. 2016. United States Department of Agriculture, Natural Resources Conservation Service. <http://plants.usda.gov>. Accessed 5 September 2016.

Vander Kloet, S.P. 1980. The taxonomy of the highbush blueberry, Vaccinium 
Highbush Blueberry Phenology

Poster et al. 25

corymbosum. Can. J. Bot. 58: 1187-1201. doi:10.1139/b80-148.

Visger, C.J., Germain-Aubrey, C.C., Patel, M., Sessa, E.B., Soltis, P.S., and Soltis, D.E. 2016. Niche divergence between diploid and autotetraploid Tolmiea. Am. J. Bot. 103(8): 1396-1406. doi:10.3732/ajb.1600130.

Vorsa, N., and Ballington, J.R. 1991. Fertility of triploid highbush blueberry. J. Am. Soc. Hortic. Sci. 116(2): 336-341. 


\section{TABLES}

Table 1. ANOVA of bloom time within diploid and tetraploid Vaccinium corymbosum bloom dates from Figure $4 . \mathrm{V}_{\mathrm{AP}}=$ Variation among plants; $\mathrm{V}_{\mathrm{AB}}=$ Variation among branches, within plants; $\mathrm{V}_{\mathrm{AF}}=$ Variation among flowers, within branches.

\begin{tabular}{|c|c|c|c|c|c|c|}
\hline Year & Ploidy & $\begin{array}{l}\text { Source of } \\
\text { Variation }\end{array}$ & $\begin{array}{c}\text { Degrees of } \\
\text { Freedom }\end{array}$ & $\begin{array}{c}\text { Sum of Squares } \\
\text { (SS) }\end{array}$ & $\begin{array}{l}\text { Mean Squares } \\
\text { (MS) }\end{array}$ & $\begin{array}{l}\text { Estimated } \\
\text { Variance }\end{array}$ \\
\hline \multirow[t]{8}{*}{2013} & $2 \mathrm{x}$ & $\mathrm{V}_{\mathrm{AP}}$ & 7 & 575.183 & 82.169 & 2.06 \\
\hline & & $\mathrm{V}_{\mathrm{AB}}$ & 16 & 326.667 & 20.417 & 1.48 \\
\hline & & $\mathrm{V}_{\mathrm{AF}}$ & 216 & 1206.800 & 5.587 & 5.59 \\
\hline & & Total & 239 & 2108.650 & -- & $9.13=V_{2 n}$ \\
\hline & $4 \mathrm{x}$ & $\mathrm{V}_{\mathrm{AP}}$ & 7 & 3043.063 & 434.723 & 12.72 \\
\hline & & $\mathrm{V}_{\mathrm{AB}}$ & 16 & 851.533 & 53.221 & 3.71 \\
\hline & & $\mathrm{V}_{\mathrm{AF}}$ & 216 & 3482.300 & 16.122 & 16.12 \\
\hline & & Total & 239 & 7376.896 & -- & $32.55=V_{4 n}$ \\
\hline \multirow[t]{4}{*}{2014} & $2 x$ & $\mathrm{~V}_{\mathrm{AP}}$ & 19 & 2981.748 & 156.934 & 5.98 \\
\hline & & $\mathrm{V}_{\mathrm{AB}}$ & 20 & 747.350 & 37.368 & 3.11 \\
\hline & & $\mathrm{V}_{\mathrm{AF}}$ & 360 & 2250.500 & 6.251 & 6.25 \\
\hline & & Total & 399 & 5979.598 & -- & $15.34=V_{2 n}$ \\
\hline
\end{tabular}




\begin{tabular}{|c|c|c|c|c|c|c|}
\hline & \multirow[t]{4}{*}{$4 x$} & $\mathrm{~V}_{\mathrm{AP}}$ & 19 & 3006.248 & 158.224 & 6.85 \\
\hline & & $\mathrm{V}_{\mathrm{AB}}$ & 20 & 426.150 & 21.308 & 1.33 \\
\hline & & $\mathrm{V}_{\mathrm{AF}}$ & 360 & 2880.700 & 8.002 & 8.00 \\
\hline & & Total & 399 & 6313.098 & -- & $16.18=V_{4 n}$ \\
\hline \multirow[t]{8}{*}{2015} & \multirow[t]{4}{*}{$2 x$} & $\mathrm{~V}_{\mathrm{AP}}$ & 19 & 2184.988 & 114.999 & 4.54 \\
\hline & & $\mathrm{V}_{\mathrm{AB}}$ & 20 & 485.850 & 24.293 & 1.87 \\
\hline & & $\mathrm{V}_{\mathrm{AF}}$ & 360 & 2017.100 & 5.603 & 5.60 \\
\hline & & Total & 399 & 4687.938 & -- & $12.00=V_{2 n}$ \\
\hline & \multirow[t]{4}{*}{$4 \mathrm{x}$} & $\mathrm{V}_{\mathrm{AP}}$ & 19 & 1142.148 & 60.113 & 2.28 \\
\hline & & $\mathrm{V}_{\mathrm{AB}}$ & 20 & 290.650 & 14.533 & 1.03 \\
\hline & & $\mathrm{V}_{\mathrm{AF}}$ & 360 & 1520.500 & 4.224 & 4.22 \\
\hline & & Total & 399 & 2953.298 & -- & $7.53=V_{4 n}$ \\
\hline
\end{tabular}


Table 2. ANOVA of bloom time of combined sympatric diploid and tetraploid Vaccinium corymbosum from Figure 5 . $\mathrm{V}_{\mathrm{AC}}$

= Variation among cytotypes; $\mathrm{V}_{\mathrm{AP}}=$ Variation among plants, within cytotypes; $\mathrm{V}_{\mathrm{AB}}=$ Variation among branches, within plants; $\mathrm{V}_{\mathrm{AF}}=$ Variation among flowers, within branches .

\begin{tabular}{cccccc}
\hline \multirow{2}{*}{ Year } & $\begin{array}{c}\text { Source of } \\
\text { Variation }\end{array}$ & $\begin{array}{c}\text { Degrees of } \\
\text { Freedom }\end{array}$ & $\begin{array}{c}\text { Sum of Squares } \\
(\mathrm{SS})\end{array}$ & $\begin{array}{c}\text { Mean Squares } \\
(\mathrm{MS})\end{array}$ & $\begin{array}{c}\text { Estimated } \\
\text { Variance }\end{array}$ \\
\hline \multirow{3}{*}{2013} & $\mathrm{~V}_{\mathrm{AC}}$ & 1 & 5490.727 & 5490.727 & 21.80 \\
& $\mathrm{~V}_{\mathrm{AP}}$ & 14 & 3618.246 & 258.446 & 8.19 \\
& $\mathrm{~V}_{\mathrm{AB}}$ & 32 & 1178.200 & 36.819 & 7.39 \\
& $\mathrm{~V}_{\mathrm{AF}}$ & 432 & 4689.100 & 10.854 & 2.60 \\
& Total & 479 & 14976.273 & -- & 39.98 \\
\hline \multirow{3}{*}{2014} & $\mathrm{~V}_{\mathrm{AC}}$ & 1 & 14519.605 & 14519.605 & 35.91 \\
& $\mathrm{~V}_{\mathrm{AP}}$ & 38 & 5987.995 & 157.579 & 7.46 \\
& $\mathrm{~V}_{\mathrm{AB}}$ & 40 & 1173.500 & 29.338 & 6.41 \\
& $\mathrm{~V}_{\mathrm{AF}}$ & 720 & 5131.200 & 7.127 & 2.22 \\
& $\mathrm{Total}$ & 799 & 26812.300 & -- & 52.00 \\
\hline \multirow{2}{*}{2015} & $\mathrm{~V}$ & 1 & 6127.245 & 6127.245 & 15.10 \\
& $\mathrm{~V}$ & 38 & 3327.135 & 87.556 & 4.09
\end{tabular}




\begin{tabular}{ccccc}
$\mathrm{V}_{\mathrm{AB}}$ & 40 & 776.500 & 19.413 & 3.41 \\
$\mathrm{~V}_{\mathrm{AF}}$ & 720 & 3537.600 & 4.913 & 1.45 \\
Total & 799 & 13768.480 & -- & 24.05 \\
\hline
\end{tabular}




\section{FIGURE CAPTIONS}

Fig. 1. A. Photo of diploid flowers (left) and tetraploid flowers (right). B. Photo of diploid flowering branch (left) and tetraploid flowering branch (right).

Fig. 2. Corolla size of diploid and tetraploid Vaccinium corymbosum. Tetraploid flowers (dark circles) are generally larger than diploid flowers (open circles), which may affect pollinator preference and a niche shift between the cytotypes.

Fig. 3. Temporal differences in bloom date of sympatric $2 \mathrm{x}$ and $4 \mathrm{x}$ Vaccinium corymbosum. Percent of total flowers in each cytotype open on a given date. Tetraploid plants have a peak bloom date that is about one week later than diploid plants. This niche shift may help the tetraploids avoid minority cytotype exclusion and become an established population by flowering when there is more tetraploid pollen available, and less diploid pollen, since triploids are mostly inviable. Light gray lines = diploid; dark grey lines = tetraploid. (A) 2013. (B) 2014. (C) 2015.

Fig. 4. Percentage of total variation within diploid and within tetraploid Vaccinium corymbosum bloom time in New Jersey, USA. Diploids and tetraploids show a similar distribution of variation among themselves and among years. White $=$ Among flower variation $\left(\mathrm{V}_{\mathrm{AF}}\right)$; Light gray = Among branch variation $\left(\mathrm{V}_{\mathrm{AB}}\right)$; Dark grey $=$ Among plant variation $\left(\mathrm{V}_{\mathrm{AP}}\right)$. (See Table 1 for ANOVA analysis.) 
Fig. 5. Percentage of total variation of combined diploid and tetraploid bloom time in New Jersey, USA. All three years show a similar distribution of variance, and the majority of the variation each year is found among cytotypes. White $=$ Among flower variation $\left(\mathrm{V}_{\mathrm{AF}}\right)$; Light grey $=$ Among branch variation $\left(\mathrm{V}_{\mathrm{AB}}\right)$; Medium grey = Among plant variation $\left(\mathrm{V}_{\mathrm{AP}}\right)$; Dark grey = Among cytotype variation $\left(\mathrm{V}_{\mathrm{AC}}\right)$. (A) 2013. (B) 2014. (C) 2015. (See Table 2 for ANOVA analysis.) 


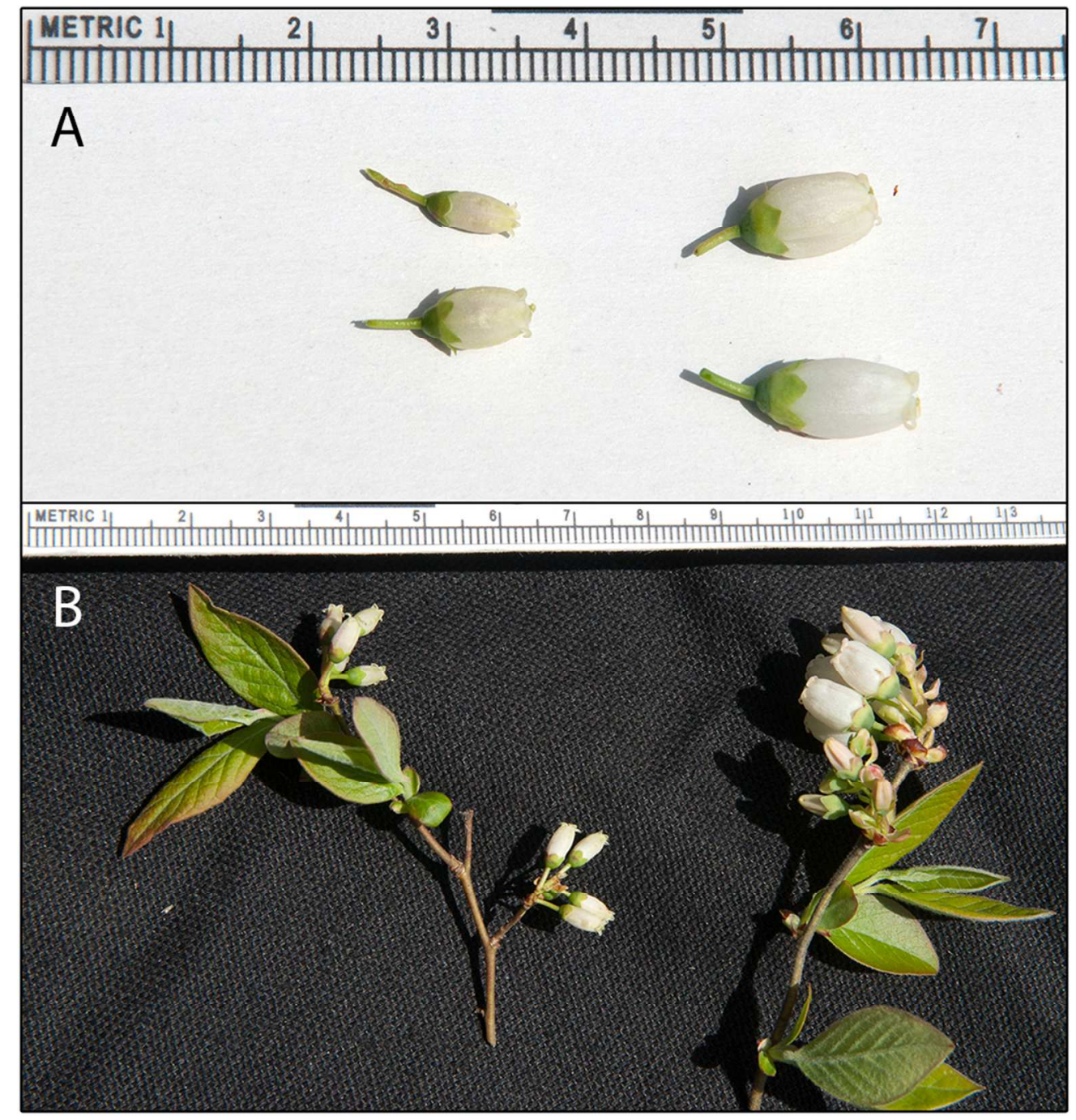

$88 \times 93 \mathrm{~mm}(300 \times 300$ DPI $)$ 


\section{Page 33 of 36}

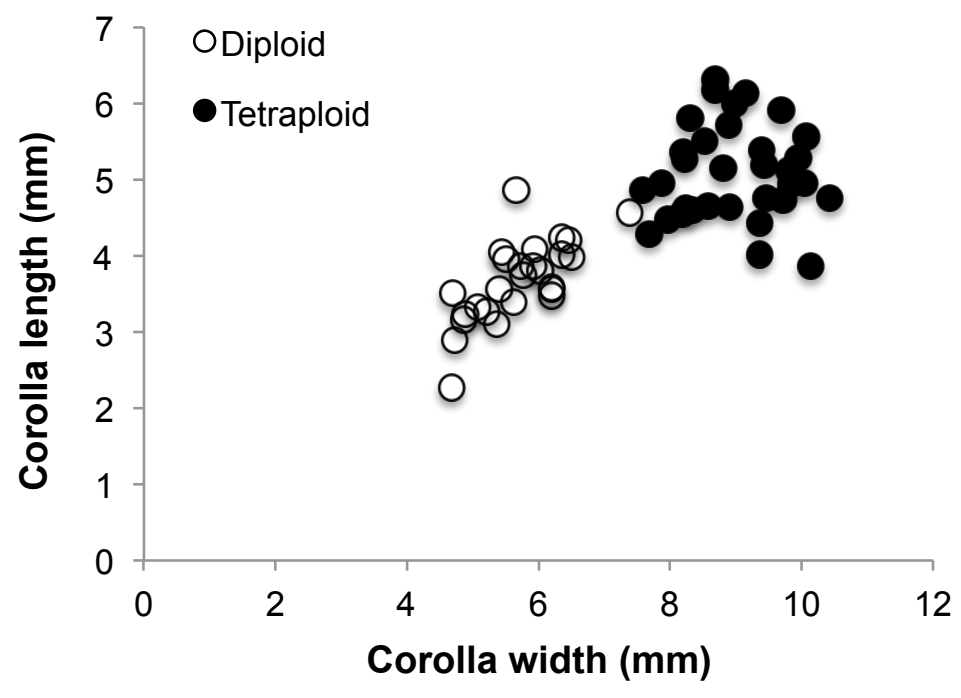



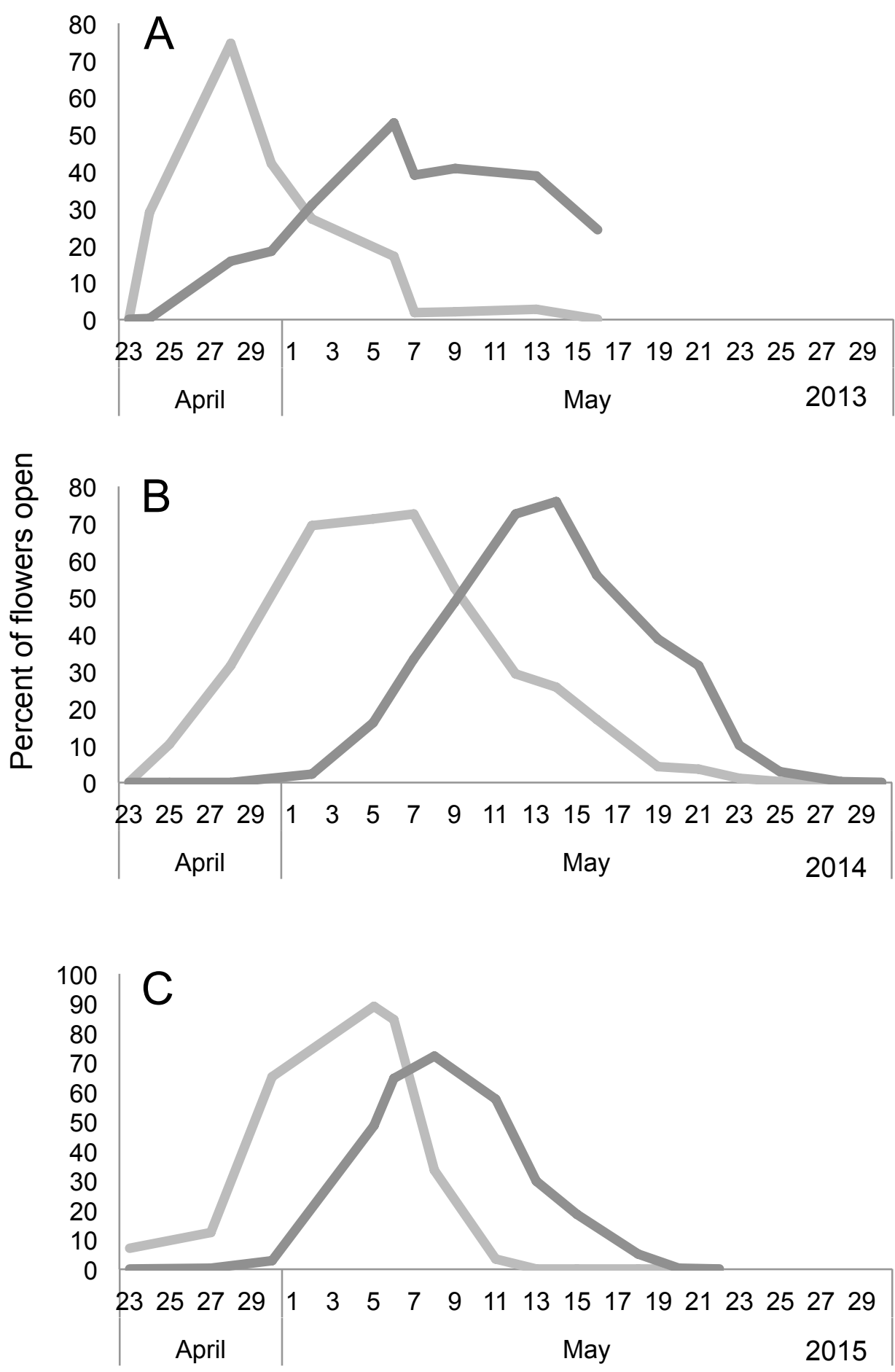

https://mc06.manuscriptcentral.com/botany-pubs 


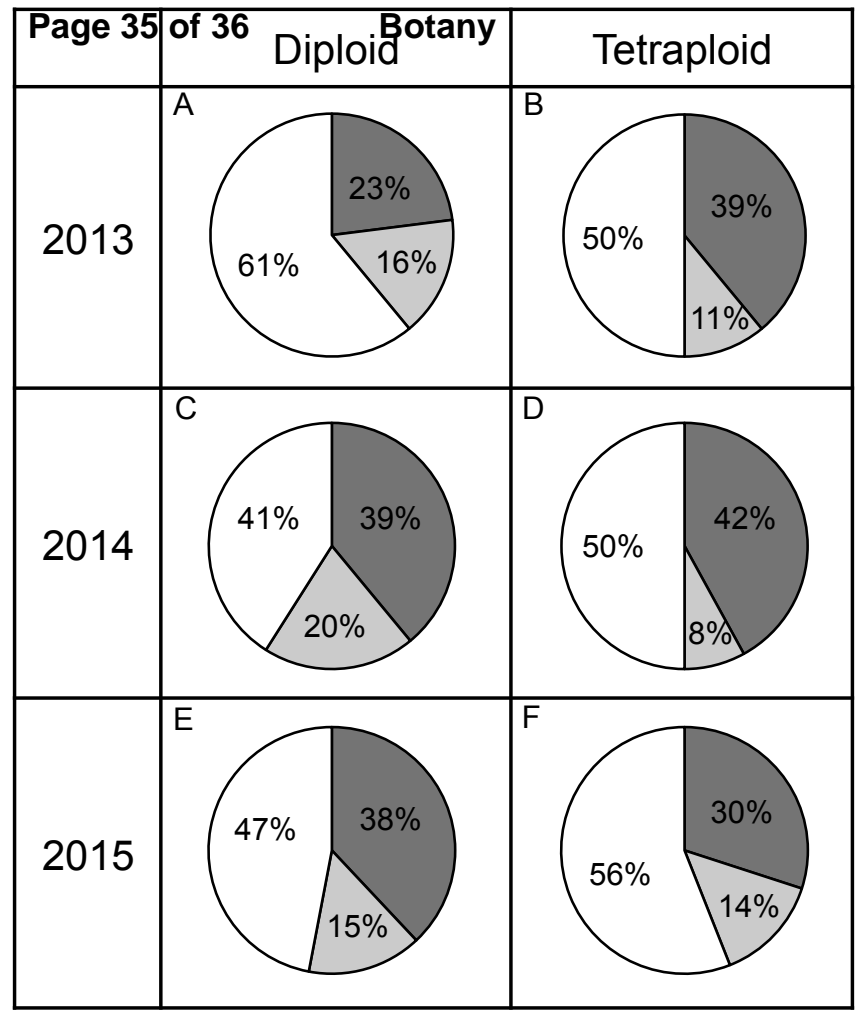

https://mc06.manuscriptcentral.com/botany-pubs 
A

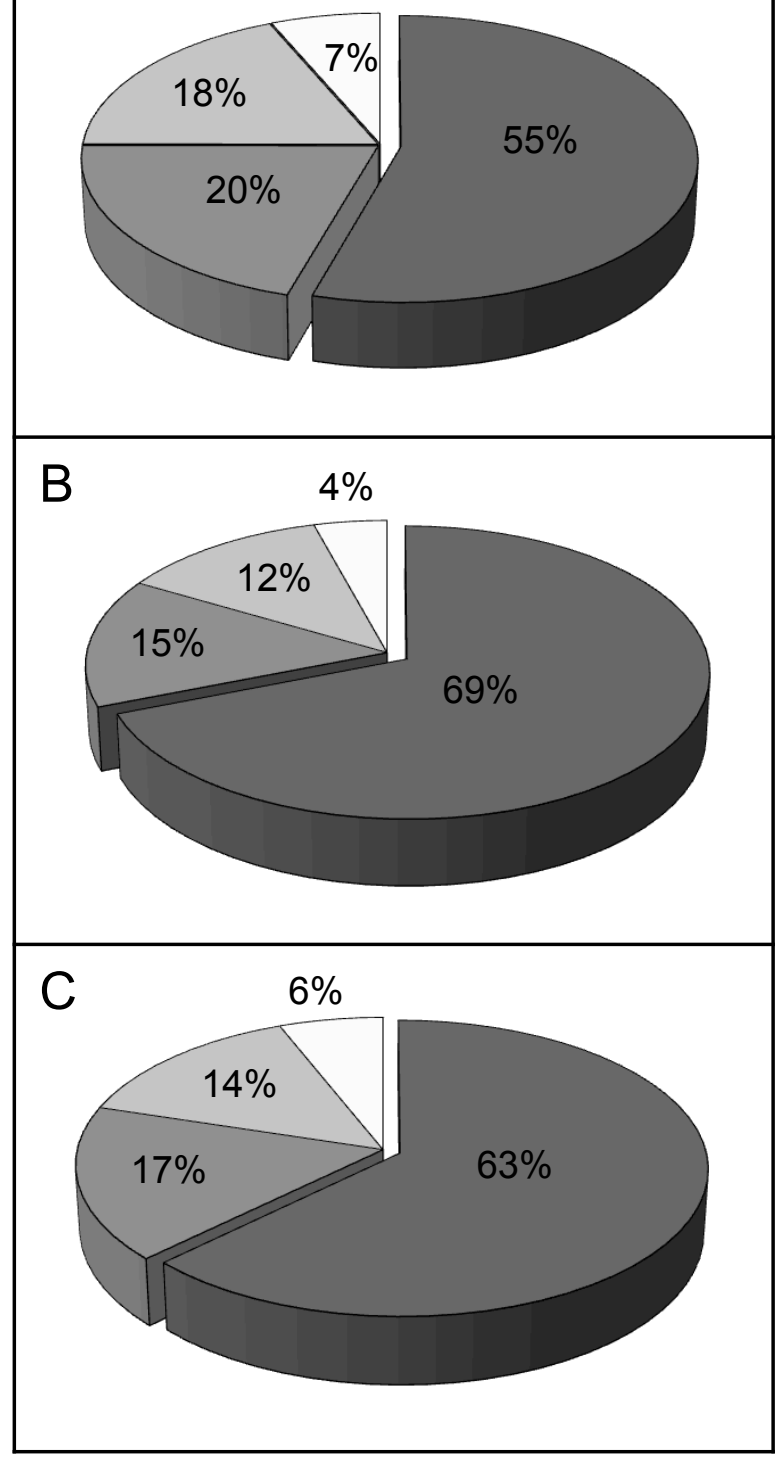

https://mc06.manuscriptcentral.com/botany-pubs 